\title{
Study on Risk Management Practices on Public Building Construction Project: In Case of Eastern Wollega Zone
}

\author{
Zelalem Mebrate \\ Department of Construction Technology and Management, College of Engineering and Technology, Wollega University, Wollega, Oromia, \\ Ethiopia
}

Email address:

zelalemwollega@gmail.com

To cite this article:

Zelalem Mebrate. Study on Risk Management Practices on Public Building Construction Project: In Case of Eastern Wollega Zone. American Journal of Civil Engineering. Vol. 9, No. 3, 2021, pp. 70-73. doi: 10.11648/j.ajce.20210903.12

Received: March 4, 2021; Accepted: May 11, 2021; Published: May 20, 2021

\begin{abstract}
This research work was tries to study the risk management practice on public building construction projects and aims to identify the level that use of risk management practice especially in the public building. The data collection method was a combination of interview and questionnaire. Samples were purposively selected from clients, consultants, and contractors representatives who are now actively participating in public building construction projects. For this study, the data was collected using both primary and secondary sources. Depending on the data that was gathered from the respondent to test the level of awareness, identifying the Risk that affect the performance of public building construction project and major risk management practice on public building construction project are considered and the RII was used to rank the factors. This data was analyzed using SPSS of version 22 to perform descriptive statistics. A total of 75 questionnaires were targeted to be distributed and out of those 50 which is $66.67 \%$ are successfully responded. The finding from this study revealed that, about $(52 \%)$ of the project progress is lagging from the schedule. Regarding the awareness of the risk management, (94\%) of the respondents where confirmed that they have awareness of risk management ideologies and they are confident enough to implement their knowledge while, $(6 \%)$ of them have no concept about the risk management. The top five risks that affect the performance of construction project have been identified and ranked. Accordingly; market condition, unexpected inflation, local taxes, inadequate production of raw materials, and the economic condition of country are the top five identified associated project risks.
\end{abstract}

Keywords: Construction Project, Public Building, Risk, Risk Management and Risk Management Practice

\section{Introduction}

Construction site is a very important place as a considerable number of works are involved in construction project activities employments in construction site can be categorized into three groups, skilled work force, semiskilled and un-skilled work force.

Safety in construction site is needed to be highly considered in order to reduce the risk of being injured to work.

Also, safety is identified as one of the major factor affecting the image of the project manager and the organized (grand jean.)."

Risk factors will cause different severity of the consequences. If one doesn't consider these risk factors at all, or ignore the main factors, they will cause damage because of decision-making errors. Quality targets, time targets, cost targets are the three major objectives of construction project management, Taking into account the above problems, the construction industry is suffering from the misunderstanding of risk management including risk identification, analysis and assessment, and that is why this research is important, where it will discover the risk factors in the public building construction project.

According to the parties involved in Ethiopian building construction projects, most projects are not completed in conformity to the original plan i.e. they face various problems and changes that lead to delay, cost overrun or lower quality. This thesis tries to study risk management practice on public building construction projects in Eastern Wollega zone and aims. 


\section{Methodology}

The articles, which had "construction safety, health hazards" as key words in this research papers, where identified. This paper has been published in journals, conference proceedings and technical reports in the respective official websites out of many articles. Risk Assessment Process

A risk assessment is a significant step in protecting your labors and your business, with fulfilling through the law. It assists you to concentrate on the risks which happened in the work site- the ones with the possibility to cause real harm. In many instances, direct events can readily control risks, for example confirming spillages are cleaned up promptly so people do not slip, or storeroom drawers are kept closed to certain individuals do not trip. Mostly, that illustrates easy, inexpensive and active actions to guarantee the maximum valued properties and workers are saved. We cannot eliminate all risk, but we are authorized to protect people as far as possible [6].

Identifying any hazards

At the first, we should recognize that in which way individuals might be affected. During the daily work is easy to control many hazards. In our project we find out many hazards during our inspection to the construction site, Such as; No Personal Protective Equipment PPE (no hard hats, no gloves), Bad fixing of mesh protection, Extra rebar, Availability of materials that contain silica (Silicosis disease) etc [1].

Also, the construction site was full of unnecessary items including pieces of machines, scaffolding materials grouped, which provide the harmful workplace for the employees and workers. In addition, all machines were not guarded and there were nip points in parts of the machines which may cause pulling off clothes and cut off fingers. The following guides are some steps to identify the hazards:

Employers must ask the workers or their agent about their ideas. They might see stuff not directly clear to employers.

Visiting the HSE website, it applied a leadership in places that hazards happened and the way of controlling them. There are enough info there on the hazards which may impact the work. Otherwise, calling HSE Info line, which classifies publications which may direct you, or by contacting Workplace Health Connect, unpaid emergency help for manager and staffs of small and medium-sized enterprises offering health and safety service in the site of work [1] for the followers of a trade organization, do a communication. Lots of them make actual supportive guideline process.

Check manufacturers' instructions or data sheets of equipment and chemical materials which are too much support in discovering the hazards and placing them in true viewpoints.

Looking to the accidents and ill-health records - are supportive in recognizing the hazards.

Never forget to think about long term hazards to health (for example, too much noise or disclosure to hurtful materials) together with safety hazards. Identifying the hazard is likely to cause harm

After the hazards were specified, then the decision on what should be done to these hazards is in a must. The law obligates us to do everything 'sensibly practicable' in saving the persons to not get harm.

The easiest way is to compare our achievements with good practice. Some good practices have been recognized. In our inspection to Uzun construction site, many hazards have been discovered and the precautions to these hazards are very essential compulsive. For instance, Scaffolding materials should be maintained and barricaded. Also all unnecessary items of machines, organs should be scrapped [8].

Identifying what control measures are already in place

For each hazard, who might be harmed should take in to a consideration; it helps you distinguish the favor approach in dealing the risk. The checklists preparing to aware the employees are very essential. In our project we find out that all staffs that are responsible for carrying out the construction site work in Uzun Company which will be harmed and badly affected, such as, skilled and manual labor, groups of carpenter, electrician, heavy equipment operators ironworkers, laborer, mason plasterer, plumber, pipefitter, sheet metal worker, steel fixer, also known as a rod buster, and welder. Each group may suffer from different dangerous injuries and illnesses, For example, heavy equipment operator might undergo backbone damage by repeating in operating and lifting heavy equipment.

Identifying what control measures are already in place

For each hazard, who might be harmed should take in to a consideration; it helps you distinguish the favor approach in dealing the risk. The checklists preparing to aware the employees are very essential. In our project we find out that all staffs that are responsible for carrying out the construction site work in Uzun Company which will be harmed and badly affected, such as, skilled and manual labor, groups of carpenter, electrician, heavy equipment operators ironworkers, laborer, mason plasterer, plumber, pipefitter, sheet metal worker, steel fixer, also known as a rod buster, and welder. Each group may suffer from different dangerous injuries and illnesses, For example, heavy equipment operator might undergo backbone damage by repeating in operating and lifting heavy equipment.

According to Health and Safety Executive, we should think of:

a lot of labors have specific necessities, for example; young labors, expectant mothers and persons with disabilities may be at specific risk. More concentration should be added to some hazards [2].

\section{Literature Review}

Health hazards and risk factor associated with construction activities, identified from previous studies are presented in this section. In addition, cause of poor safety practices and possible methods to enhance safety practices were also identified. 


\subsection{Health Hazards and Risks}

A hazard is a potential source of harm or an adverse health effect on persons. Risk is the likelihood that a person may be harmed or suffered from adverse health effects if exposed to a hazard. Therefore risk can be minimized although the hazard is there. Two major hazards that common in construction site have been identified. Two major hazards that are common in construction site have been identified by [8].

\subsection{Cause of Poor Safety Practice}

Possible causes of poor safety practices that were identified from safety equipment, safety management, and safety attitude of workers, safety training and others. Chemical hazards found in construction work include asbestos, welding, fumes, spray paints; cutting oil mists solvents and others [7].

\subsection{Overview of Project and Its Lifecycle}

In defining a project, Larson and Gray (2011) described it as a non-permanent venture carried out to create a specific outcome of product, service, or results and it's characterized by the following: A set objective, Time constraint, Budget constraint, desired performance criteria, and Engagement of distinct sectors and professionals. [3] On the other hand describes a Project as a chain of activities with a set start and close date that holds a specific objective to be realized within the constraint of time, cost, and resources.

\subsection{Risks in the Project Life Cycle Cost}

To make sure that everybody connected with a project is aware what a risk is, one common definition should be drawn up for the purpose of the particular project. To quantify identified risks, [3] uses a tool where likelihood of occurring risk is rated.

Risks are associated with every project and should be identified in order to avoid negative impacts on the overall performance. Many problems which are faced in later phases of the PLC result from unmanaged risks from the earlier stage this indicates how important it is to carry out accurate analysis especially in an initial phase of a project [8] Perceive $\mathrm{RM}$ as a process which starts at project definition and continues through planning, execution, control and closure phase. However, a study conducted by Lyons and Skit more (2002) proves that planning and execution are the two phases where RM is most widely used.

\section{Discussions}

By comparing health hazards, in different studies depending on the type of construction site worker may expose too many healthy problems.

This part of the research deal with the analysis and discussion of data collected from questionnaire survey and interviews. The questionnaire was developed based on the literature review of this research study as well as from research questions.

The research studies show that the developing country does not pay attention for both chronic and acute hazards and different contractors have different perception toward health hazards.

Unexpected inflation is ranked $2^{\text {nd }}$ in the overall group of factor and $1^{\text {st }}$ in his group according to the expectation of the respondents also $100 \%$ of respondent and interviewer are believe the effect of Unexpected inflation is risk that affect the performance in public building construction project and also for the question is it Unexpected inflation is affect risk management performance is hundred percent of the respondents are say yes with in relative importance index of 0.81 . Increase of material price/unexpected inflation/ $2^{\text {nd }}$ not only in the group but also among the 59 factors. The factor was ranked very highly impact according to the respondent rate of response, as from discussions have stated that the increase of material price/fluctuation/is a major factor that affects the performance of public building construction project. In recent years in Ethiopia as a result of the successive economic growth, the price of materials on the market is observed to be very unstable. The price of everything has greatly increased and is being increased. The construction sector is one of the victims of this high price rise of inputs; and the main actors of construction are contractors who are sustaining the damage at the front line. In other words, the unexpected inflation is unpredictable that contractors cannot easily determine how the price of materials can go on, it can be seen that the price fluctuation of these inputs can be fairly predictable, that is contractors can fairly determine how the price of these inputs will go on based on other factors this is agrees and supported in the paper that is done by [4]. For to improve the problem of unexpected inflation the government must have considered the price of material from time to time; also during the agreement contractor and clients are to take consideration depending on the duration of the project the detail is give in the following figure.

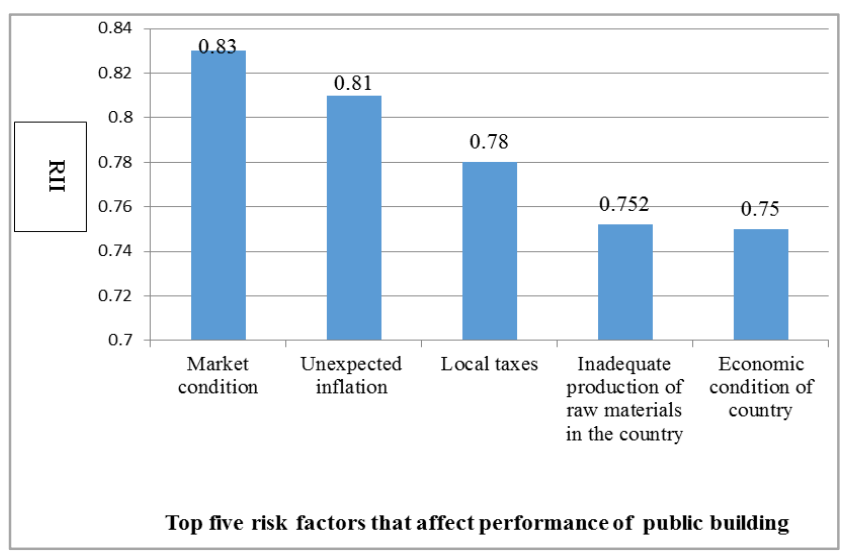

Figure 1. Top five risk factors that affect performance of public building.

In this study let as seen the percent of the respondents say yes and no to practice risk management in his /her organization at different cycle of the project stages. Among the group which don't use risk management techniques around $(42.9 \%)$ put down lack of awareness as their main 
reason.

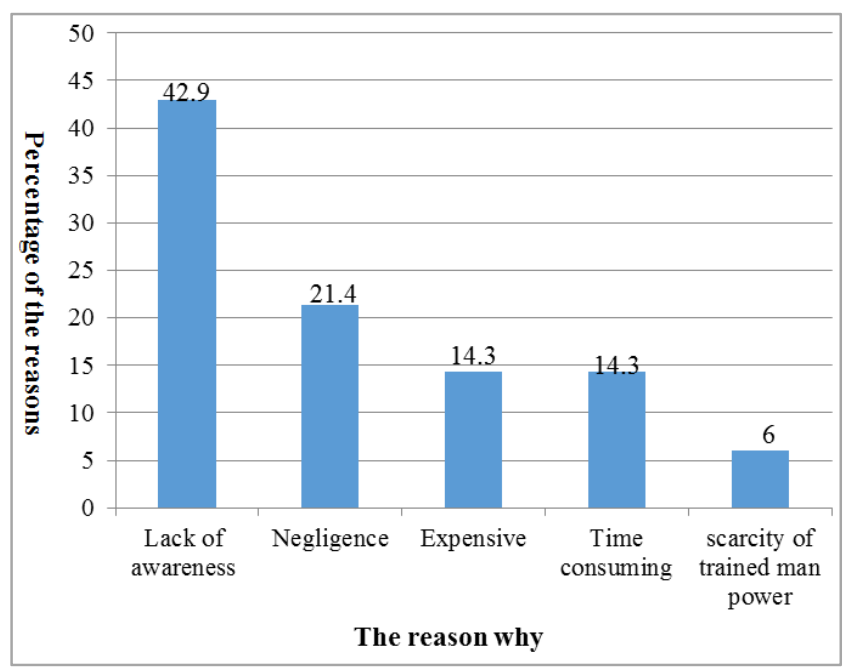

Figure 2. Practice risk management in percent.

\section{Conclusions}

The objective of this thesis was clearly stated in the introduction part and to achieve the objective, factors were identified; the questionnaire was prepared and filled by contractors, clients, and consultants. The major finding of the research which has already discussed was summarized. Finally, the following conclusions were drawn.

1) From the survey data analysis researcher were conclude that, about (52\%) of the project progress is lagging from the schedule and also not finalized within a given budget because there is increment of time proportionally, depending on this analysis we can possible to say more than $50 \%$ of the project is lagging from the schedule. Consequently, there is a different risk factor that affects the progress of project accordingly because $52 \%$ of the projects are not finished within a given schedule and budget.

2) The ways become the respondents aware the opinion of risk management are: $(52 \%)$, were first aware of risk management practices through experience, $(24 \%)$ of the respondents gained their awareness through study, $(22 \%)$ of them through workshop and training and $(2 \%)$ were aware of risk management through reading.

3) Most of the parties involved in the Ethiopian building construction projects are aware of the concept of risk management, but only a relatively smaller number of this group believe they have an adequate knowledge needed for applying these risk management techniques to make their projects successful.

4) The top five risk rated by their level of effect and frequency of occurrence that affect the performance of construction project from the data analysis are: - Market condition, unexpected inflation, local taxes, inadequate production of raw materials in the country and the Economic condition of country.

5) Generally the seventy $70 \%$ of respondents say yes were practice risk management techniques at the different cycle of the construction project, from those $(38 \%)$ of the during construction stages, (4\%) during planning and design stage, $(8 \%)$ during tendering time and (22\%) of the respondents are practice risk management techniques at all stage of the construction project in public building construction project in case of Eastern Wollega zone.

6) While the remaining $30 \%$ stated they don't use any risk management practice because of different reason, from those (42.9\%) lack of awareness (21.4\%) negligence, $(14.3 \%)$ of the expensiveness and time consuming and six percent $(6 \%)$ of the respondents are say scarcity of trained man power.

\section{Acknowledgements}

First of all, I thank the Almighty God for making this work possible. I am incredibly much indebted to my thesis advisor Alemu Mosisa (Assistant Professor) for his critical and professional comment, constructive criticism, suggestion and useful advice that have improved the quality of my work and also helped my career at large and for all his advice, motivation, kind support and guidance during the course of writing this thesis.

I also extend my sincere gratitude to all individuals those directly or indirectly helped me to realize this thesis, especially my respondents' (clients, contractors, and consultants) of the Eastern Wollega zones for their kindness and expert treatment in responding my questionnaires and Interviews. Lastly but not the least, I like to thank my spouse and my parents for their Motivations, Love and Support in my live at all.

\section{References}

[1] Dikemet. (2007). Construction management and risk categories. Catigorized risk in Construction project. D, H. (n.d.). managing risk.

[2] Hillson. D. (2015). Risk management implimentation in construction project. Risk management discipline.

[3] Kerzner. (2007). Construction project overall management.

[4] Mesfin Aklilu. (2006). Communication between the Stakeholders.

[5] Mills. A. (2001). risk management perception and trend in USA construction and a systematic approachto risk management. $J$. $N$ construction engineering and management.

[6] Nerkus, B. A. (2011). Risk management in Projects. International journal of strategic property management, 15, 60-73.

[7] Pendleburyet. (2003). Construction risk on the site against an employee.

[8] Salahaddin. (2017). Risk mitigation mechanism hand book. internation journal for risk management minimization. 